\section{Topic reviews need to be robust}

To the Editor: I note with interest the review entitled 'Heart failure in sub-Saharan Africa: A clinical approach. ${ }^{[1]}$

It is very concerning that the only heart failure guideline published in Africa was not referenced in this review. ${ }^{[2]}$ The Heart Failure Society of South Africa (HeFSSA) is the only official heart failure society in Africa. The HeFSSA guideline was published as a modification of the European Society of Cardiology guideline that is quoted in the review, ${ }^{[3]}$ specifically to impart a 'sub-Saharan' perspective.

If the HeFSSA guideline was included in this review then I'm sure the significant omission of the hydralazine-nitrate oral combination as a crucial arm of chronic heart failure therapy would not have occurred. Considering the demographics of sub-Saharan Africa, omitting a therapy that has proven to significantly improve survival, reduce hospitalisations and improve quality of life in black Africans, ${ }^{[4]}$ is most unfortunate.

The review also includes perindopril $2-4 \mathrm{mg}$ in their list of suggested angiotensin-converting enzyme (ACE) inhibitors. The HeFSSA guideline excluded this particular drug as no large randomised data exist for the efficacy of this drug in heart failure, not to mention the recommended dose. Perindopril $4 \mathrm{mg}$ as a single drug had no benefit on reducing stroke, ${ }^{[5]}$ and perindopril $8 \mathrm{mg}$ was needed to reduce events in high-risk cardiovascular patients. ${ }^{[6]}$ The effective dose in heart failure is unknown. Telmisartan is also included in this review. No heart failure end point and effective dose data exist for this drug either and it is not listed in the HeFSSA guideline.

The comments in the review on a heart rate target of $<75$ beats/ minute with beta-blocker therapy are confusing and ill advised for the heart failure practitioner. No large, randomised beta-blocker trial that showed improved survival and reduced hospitalisations in chronic heart failure therapy has used heart rate as a target in therapy. Target beta-blocker doses were aimed for in the trials and should be aimed for in clinical therapy. The statement in this review confuses the systolic heart failure treatment (SHIFT) ${ }^{[7]}$ trial and extrapolates inappropriately the heart rate data to beta-blocker therapy with no randomised evidence to support this advice. This advice in the review will also result in underdosing of beta-blocker therapy. If this review ${ }^{[1]}$ is to be used as a reference for doctors to guide their heart failure therapy, then I strongly suggest corrections should be published in a revised review.

\section{Eric Klug \\ President of the Heart Failure Society of South Africa, Heart Failure Clinic, Charlotte Maxeke Johannesburg Academic Hospital, and Sunninghill Hospital, Johannesburg, South Africa \\ eklug@global.co.za \\ 1. Kraus S, Ogunbanjo G, Sliwa K, Ntusi NA. Heart failure in sub-Saharan Africa: A clinical approach. S Afr Med J 2016;106(1):23-31.DOI:10.7196/SAMJ.2016.v106i1.10325 \\ 2. Mpe, MT, Klug, EQ, Sliwa, KS, et al. Heart Failure Society of South Africa (HeFSSA) perspective on the European Society of Cardiology (ESC) 2012 chronic heart failure guideline. S Afr Med J 2013;103(9 Suppl 2):661-667. DOI:10.7196/SAMJ.7319 \\ 3. McMurray JI, Adamopoulos S, Anker SD, et al. ESC guidelines for the diagnosis and treatment of acute and chronic heart failure 2012: The Task Force for the Diagnosis and Treatment of Acute and Chronic Heart Failure 2012 of the European Society of Cardiology. Developed in collaboration with Chronic Heart Failure 2012 of the European Society of Cardiology. Developed in collaboration with
the Heart Failure Association (HFA) of the ESC. Eur Heart J 2012;33(14):1787-1847. DOI:10.1093/ the Heart Failure
eurheartj/ehs104 \\ 4. Taylor, AL, Ziesche S, Yancy C, et al. Combination of isosorbide dinitrate and hydralazine in blacks Taylor, AL, Ziesche S, Yancy C, et al. Combination of iso
with heart failure. N Engl J Med 2004;351(20):2049-2057. \\ 5. PROGRESS Collaborative Group. Randomised trial of a perindopril-based blood-pressure-lowering regimen among 6,105 individuals with previous stroke or transient ischaemic attack. Lancet 2001;358(9287):1033-1041. DOI:10.1016/\$0140-6736(01)06178-5 \\ 6. Fox KM, EURopean trial On reduction of cardiac events with Perindopril in stable coronary Artery disease Investigators. Efficacy of perindopril in reduction of cardiovascular events among patients with stable coronary artery disease: randomised, double-blind, placebo-controlled, multicentre trial (the EUROPA study). Lancet 2003;362(9386):782-788. DOI:10.1016/S0140-6736(03)14286-9 \\ 7. Swedberg K, Komaida M, Böhm M, et al Ivabradine and outcomes in chronic heart failure (SHIFT): A randomised placebo-controlled study. Lancet 2010;376(9744):875-885. DOI:10.1016/S0140- 6736(10)61198-1}

Ntusi et al. respond: We are grateful for the opportunity to respond to the comments made by Dr Klug in reference to our article titled
"Heart Failure in sub-Saharan Africa: A clinical approach, ${ }^{[1]}$ which formed part of the recent cardiovascular disease (CVD) continuing medical education (CME) in the Journal. Indeed, the heart failure (HF) guideline ${ }^{[2]}$ published under the auspices of the Heart Failure Society of South Africa (HeFSSA) was not cited in this review. We admit this was an important omission. However, our review liberally cited the European Society of Cardiology (ESC) guideline on the management of $\mathrm{HF}^{[3]}$ upon which the HeFSSA guideline is also heavily premised.

While we acknowledge the importance of the HeFSSA guideline and its place in the management of HF in South Africa (SA), the HF review, which was not meant to replace the current treatment recommendations of HeFSSA, like all the articles that formed the CVD CME, focused on simple, pragmatic clinical approaches to common cardiovascular challenges encountered at the primary level of healthcare, with the aim of not being overly complex. As such, in this successful collaboration, the CME articles were jointly produced by SA cardiologists and family physicians with the dual objectives of empowering doctors who manage these conditions in primary care settings in SA and improving the care of CVD patients in such settings. In the first issue, $\mathrm{HF},{ }^{[1]}$ dyspnoea ${ }^{[4]}$ hypertension in the young ${ }^{[5]}$ and valvular heart disease ${ }^{[6]}$ were reviewed. In the second issue, infective endocarditis ${ }^{[7]}$ and pericardial disease ${ }^{[8]}$ were discussed. The final edition provided an evidence-based and pragmatic approach to chest pain and acute coronary syndromes ${ }^{[9]}$ and suspected tachyarrhythmias in the emergency room. ${ }^{[10]}$

Upon this background, the main goals of the HF review were to: (i) emphasise how to make the diagnosis of HF; (ii) highlight clues for recognition of the underlying aetiology of HF; (iii) review the pathophysiology of HF; and (iv) provide a simplified approach to management of HF.

The lack of recommendations relating to use of hydralazinenitrate oral combination in our HF review, in particular for black African patients, are indeed a notable omission. In the SA public sector, particularly at the primary healthcare level, the availability of hydralazine is haphazard. Further, while this combination therapy is associated with improved survival, reduced hospitalisation and improved quality of life in black African patients, compared with placebo, it is comparable with the mortality benefit of angiotensin converting enzyme (ACE) inhibitors, which are much more freely available and accessible in primary health centres around SA. Moreover, this combination therapy should be used with caution in certain patients. ${ }^{[1]}$ In addition, the recently performed Bi treatment with hydralazine/ nitrates v. placebo in black Africans admitted with acute HF (BA-HEF) study had to be terminated prematurely due to poor recruitment and was neutral. ${ }^{[12]}$ One of the main reasons for poor recruitment was hypotension.

Even though perindopril does not have randomised trial data supporting its specific use in HF, in certain provinces within SA such as the Eastern Cape, it has been the only ACE inhibitor available within the state sector, and it is still included (at the doses stated in our HF review) in the ESC guidelines. ${ }^{[3]}$ We have opted to adopt a pragmatic approach that is relevant to primary healthcare practitioners in SA.

The comments relating to target heart rate with beta-blockers are noted and we share the same views as Dr Klug. Indeed, there is no evidence of improved outcomes with beta-blockers titrated to a specific target heart rate. However, there is strong evidence that heart rate reduction in HF is associated with improved survival, ${ }^{[13,14]}$ although the optimal heart rate target has not been established. 
It is our hope that our review will provide a simple and pragmatic clinical approach to the management of HF at the primary healthcare level in SA in order to improve the lives of SA HF patients.

\section{Ntobeko A B Ntusi}

Lecturer and Fellow, Division of Cardiology, Department of Medicine,

Faculty of Health Sciences, University of Cape Town and Groote Schuur Hospital,

Cape Town, South Africa

ntobekontusi@gmail.com

\section{Sarah M Kraus}

PhD Candidate, Division of Cardiology, Department of Medicine, Faculty of Health Sciences, University of Cape Town and Groote Schuur Hospital, Cape Town, South Africa

\section{Gboyega Ogunbanjo}

Head, Department of Family Medicine and Primary Health Care, Sefako Makgatho Health Sciences University, Pretoria, South Africa

\section{Karen Sliwa}

Professor of Cardiology, Division of Cardiology, Department of Medicine, Faculty of Health Sciences, University of Cape Town and Groote Schuur Hospital, Cape Town and Director, Hatter Institute for Cardiovascular Research in Africa, Department of Medicine, Faculty of Health Sciences, University of Cape Town, Cape Town, South Africa

1. Kraus S, Ogunbanjo G, Sliwa K, Ntusi NA. Heart failure in sub-Saharan Africa: A clinical approach. S Afr Med J 2016;106(1):23-31. DOI:10.7196/samj.2016.v106i1.10325

2. Mpe MT, Klug EQ, Silwa KS, Hitzeroth J, Smith DA. Heart Failure Society of South Africa (HeFSSA) perspective on the European Society of Cardiology (ESC) 2012 chronic heart failure guideline. S Af Med J 2013;103(9, Suppl 2):660-667. DOI:10.7196/samj.7319
3. McMurray JJ, Adamopoulos S, Anker SD, et al. ESC guidelines for the diagnosis and treatment of acute and chronic heart failure 2012: The Task Force for the Diagnosis and Treatment of Acute and Chronic Heart Failure 2012 of the European Society of Cardiology. Developed in collaboration with the Heart Failure Association (HFA) of the ESC. Eur Heart J 2012;33(14):1787-1847. DOI:10.1093/ eurhearti/ehs104

4. Coccia CB, Palkowski GH, Schweitzer B, Motsohi T, Ntusi NA. Dyspnoea: Pathophysiology and a clinical approach. S Afr Med J 2016;106(1):32-36. DOI:10.7196/samj.2016.v106i1.10324

5. Mangena P, Saban S, Hlabyago KE, Rayner B. An approach to the young hypertensive patient. S Afr Med J 2016;106(1):36-38. DOI:10.7196/samj.2016.v106i1.10329

6. Cupido BJ, Peters F, Ntusi NA. An approach to the diagnosis and management of valvular heart disease. S Afr Med J 2016;106(1):39-42. DOI:10.7196/samj.2016.v106i1.10326

7. Hitzeroth J, Beckett N, Ntuli P. An approach to a patient with infective endocarditis. S Afr Med J 2016;106(2):145-150. DOI:10.7196/SAMJ.2016.v106i2.10327

8yriakakis CG, Mayosi BM, de Vries E, Isaacs A, Doubell AF. An approach to the patient with suspected pericardial disease. S Afr Med J 2016;106(2):151-155. DOI: 10.7196/SAMJ.2016.v106i2.10328

9. Pandie S, Hellenberg D, Hellig F, Ntsekhe M. An approach to chest pain and acute myocardial infarction. S Afr Med J 2016;106(3):239-245. DOI:10.7196/SAMJ.2016.v106i3.10323

10. Chin A, Vezi B, Namane M, Weich H, Scott-Millar R. An approach to the patient with suspected tachycardia in the emergency department. S Afr Med J 2016;106(3):246-250. DOI:10.7196/SAMJ.2016. 3.10322

11. Elkayam U, Bitar F. Effects of nitrates and hydralazine in heart failure: Clinical evidence before the African American Heart Failure Trial. Am J Cardiol 2005; 96(7B):37i-43i. DOI:10.1016/j. amjcard.2005.07.031

12. Sliwa K, Damasceno A, Davison BA, et al. Bi treatment with hydralizine/nitrtaes versus placebo in Africans admitted with acute heart failure (BA-HEF). Eur $\mathrm{J}$ Heart Fail 2016(in press).

13. Swedberg K, Komajda M, Böhm M, et al. Ivabradine and outcomes in chronic heart failure (SHIFT): A randomised placebo-controlled study. Lancet 2010;376(9744):875-885. DOI:10.1016/S01406736(10)61198-1

14. McAlister FA, Wiebe N, Ezekowitz JA, et al. Meta-analysis: Beta-blocker dose, heart rate reduction, and death in patients with heart failure. Ann Intern Med 2009;150(11):784-794. DOI:10.7326/0003-4819150-11-200906020-00006

S Afr Med J 2016;106(7):644-645. DOI:10.7196/SAMJ.2016v106i7.10903 